\title{
Assessment of Child Immunization Coverage and Associated Factors in Oromia Regional State, Eastern Ethiopia
}

\author{
Hussen Mohammed $^{1 *}$ and Alemayehu Atomsa ${ }^{2}$ \\ ${ }^{1}$ School of Medicine,Dire Dawa University, Dire Dawa, Ethiopia \\ ${ }^{2}$ Jimma University, Public Health Faculty, Department of Epidemiology and Biostatistics, Jimma, Ethiopia
}

\begin{tabular}{|c|c|}
\hline Abstract & Article Information \\
\hline \multirow{12}{*}{$\begin{array}{l}\text { The aim of the study is to assess the immunization coverage of children aged } \\
\text { between } 12-23 \text { months and its determinants. A community based cross-sectional } \\
\text { survey involving quantitative and qualitative study was conducted from } 1-24 \text { March, } \\
2010 \text { in } 6 \text { Kebeles of Kombolcha district. Stratified multi-stage cluster sampling } \\
\text { technique with simple random sampling (SRS) was used to select sample size of } \\
694 \text { children aged } 12 \text { to } 23 \text { months with their mothers or care takers after census } \\
\text { conducted in randomly selected Kebeles. Data was collected by using pre-tested } \\
\text { structured questionnaire and then coded, edited, entered and analyzed by using } \\
\text { SPSS version } 16.0 \text { software. Of total } 168(24.2 \%) \text { not immunized, } 367(52.9 \%) \\
\text { partially immunized and } 159(22.9 \%) \text { completely immunized. The BCG, OPV } 1 \text {, } \\
\text { OPV3, pentavalent-1, pentavalent- } 3 \text { and measles coverage at the time of survey by } \\
\text { card plus history was } 452(65.1 \%) \text {, } 520(74.9 \%) \text {, } 236(34.0 \%) \text {, } 512(73.8 \%) \text {, } \\
230(33.1 \%) \text { and } 280(40.3 \%) \text { respectively. Unaware of the need of immunization, } \\
\text { they didn't return for } 2^{\text {nd }} \text { and } 3^{\text {rd }} \text { dose because of fear of the side reaction, lack of } \\
\text { information on place and/or time of immunization and wrong perception about } \\
\text { contraindication were statistical significant factors for partially immunize their } \\
\text { children. Over all the immunization coverage in Kombolcha Woreda was low that to } \\
\text { in case of pentavalent-3 (33.1\%). To prevent defaulters' mothers/ care takers should } \\
\text { be given due attention, encouraged and promoted during contacts. }\end{array}$} & $\begin{array}{l}\text { Article History: } \\
\text { Received : 03-01-2013 }\end{array}$ \\
\hline & Revised : :04-03-2013 \\
\hline & Accepted : 18-03-2013 \\
\hline & Keywords: \\
\hline & Immunization \\
\hline & Coverage \\
\hline & Determinants \\
\hline & ${ }^{\star}$ Corresponding Author: \\
\hline & Hussein Mohammed \\
\hline & $\mathrm{E}$ \\
\hline & hus.aliya@gmail.com \\
\hline & \\
\hline
\end{tabular}

\section{INTRODUCTION}

The EPI (expanded program of immunization) was launched in 1974 as a global program for the control of Vaccine-preventable diseases (VPDs). According to $\mathrm{WHO}$ vaccine coverage is estimated as by convention, with DPT3 coverage achieved among children aged 12-23 months (Forder, 2002 and WHO, 2006). At end of 2006, immunizations saved 2-3 million lives nonetheless, in the same year 1.4 million children are estimated to have died from VPD (measles, $\mathrm{H}$-influenza B, Pertusis, tetanus, yellow fever, and poliomyelitis),a reflection of the incomplete coverage with existing vaccines that persists in many parts of the world (Tove, et al., 2008; $\mathrm{FMOH}$ et al., 2004). Infant mortality rate stood at 77, 76 and under five mortality was 123, 123 per thousand live births for Ethiopia and Oromia regional state respectively. Reducing under five mortality to $67 / 1000$ by 2015 can only be achieved if cost effective and high impacts interventions developed in support of the child health program that are implemented at very high levels of coverage, which includes among others: Reaching Every Districts (RED) strategy, Integrated Management of Child IIIness (IMCl) and Enhanced Outreach Strategy (EOS) (Government of Ethiopia, 2007).

In 1980, the government of Ethiopia implemented EPI with goal of increasing vaccination coverage against the six childhood killer diseases by $10 \%$ each year to reach $100 \%$ coverage in 1990, this program goal has largely remained unrealized even using different efforts. 
Hussen Mohammed et al.,

Despite the high prevalence of VPDs in the country, immunization coverage rates stagnated and remained very low for many years. As a result many children in Ethiopia do not get the benefits of immunization (Berhane, 2008). To increase the immunization coverage in Ethiopia, assessing factors affecting immunization has to be identified through community based study. Such community based study is not available in Ethiopia. The objective of the study was to assess immunization coverage of children aged 12-23 months and associated factors in Kombolcha district, East Hararghe, Oromia regional state, Ethiopia.

\section{MATERIALS AND METHODS}

\section{Ethical Consideration}

Ethical clearance was obtained from the Ethical review Committee of Jimma University. Before data collection, written consent was obtained from the respondents.

The study was conducted in Kombolcha Woreda of East hararghe zone of Oromia Regional State from March 1 to 24/ 2010. There are 20 Kebeles (small administrative units) in Kombolcha Woreda of these one urban Kebele (Malka Rafu) and the remaining 19 are rural Kebeles. WHO multi-stage cluster sampling with stratification (WHO, 2005) was used in which the Woreda was first stratified into urban and rural Kebeles based on residents that is 20 Kebeles (one urban and 19 rural Kebeles), 5 clusters/ Kebeles were selected from 19 rural Kebeles at first stage by lottery method and one urban kebele is included. To identify the households that had been eligible child (12 to 23 months) the census was conducted for one urban Kebeles and 5 randomly selected rural Kebeles. After households (mothers/care takers) with eligible children were identified as sampling frame, simple random sampling (SRS) was employed to select proportionally allocated sample for each selected Kebeles.

The numbers of children sampled within each selected Kebeles of Woreda were allocated based on the size of children between 12 and 23 months age in the Kebeles. For those households having more than one child in households, one child was selected randomly per household during census.

Two day training sessions including field exercises were conducted to train supervisors and data collectors. In addition to the standard WHO EPI data collection forms, the instruments were constructed from review of available literature on immunization coverage (CSA, 2006;
Sci. technol. arts Res. J., Jan-Mar 2013, 2(1): 36-41

Olumuyiwa et al., 2008). The instrument consisting of background, knowledge and attitude on immunization, source and types of information on immunization, history of vaccines received by the child and reasons for no vaccination were administered to mothers or care takers of the child by trained interviewers, access to health service (distance of health facility from home in kilometer or time taken to reach health facility, waiting time in minutes). The data collectors ask mothers or care takers vaccination cards, if present cope the vaccine received by child on instrument and if card absent fill instrument by history.

\section{Statistical Analysis}

Data were entered to SPSS Version 16.0 after checking for completeness, then cleaned and analyzed accordingly. Descriptive and analytical statistics including univariate, bivariate and multivariable analysis were employed. Bivariate analysis and chi-square test were used to examine association between dependent and independent variables; a corresponding $p$-value of $<0.05$ was considered to be statistically significant with $95 \% \mathrm{Cl}$. To identify the independent factor that influences immunization completion, reason of not immunizing or partially immunizing their children multivariable logistic analysis was carried out.

\section{RESULTS}

Six hundred ninety four respondents with 12-23 months children participated. The majority of the respondents were mothers, $685(98.7 \%)$ but only $9(1.3 \%)$ care takers were involved in the study.

Educational level of the mothers/care takers, $458(60 \%)$ were not able to write and read, those able to read and write mothers/care takers were only $120(17.3 \%)$ but the education of children's father not notable from mothers/care takers however somewhat better $270(38.9 \%)$ were not able to write and read and $190(24.4 \%)$ were able to read and write.

The sex of index child: males 354(51.0\%), females $340(49.0 \%)$ and of the total index children $515(74.2 \%)$ were in age range 12 to 18 months, 19 to 23 months age children were $179(25.8 \%)$ and with mean age 16.39 months $( \pm 3.23 S D)$.

High proportion of children, $577(83.1 \%)$ were delivered at home, $86(12.4 \%), 31(4.5 \%)$ were delivered at public and private health institution respectively. 
Hussen Mohammed et al.,

The information on immunization coverage was collected in two ways: from immunization cards shown to the interviewer and from mothers' verbal reports. Of those immunized children the
Sci. technol. arts Res. J., Jan-Mar 2013, 2(1): 36-41 card retention rate (those vaccinated by card) was $245(46.6 \%)$ and $281(53.4 \%)$ vaccinated according to maternal/care takers history (Table 1).

Table1: Immunization by source of information (immunization card or mother's report) in eastern Ethiopia, 2010.

\begin{tabular}{llll}
\hline & \multicolumn{2}{c}{ Source of information } & \\
Vaccines & Immunization Card & Maternal History & Total \\
\hline BCG & $235\left(33.9^{*}\right)$ & $217(31.1)$ & $452(65.1)$ \\
OPV0 & $32(4.6)$ & $19(2.7)$ & $51(7.3)$ \\
OPV1 & $243(35.0)$ & $277(39.9)$ & $520(74.9)$ \\
OPV2 & $187(26.9)$ & $227(32.8)$ & $417(59.7)$ \\
OPV3 & $143(20.6)$ & $93(13.4)$ & $236(34.0)$ \\
Pentavalent1 & $243(35.0)$ & $269(38.8)$ & $512(73.8)$ \\
Pentavalent2 & $193(27.8)$ & $223(32.1)$ & $426(59.9)$ \\
Pentavalent3 & $147(21.2)$ & $83(11.9)$ & $230(33.1)$ \\
Measles & $113(16.3)$ & $167(24)$ & $280(40.3)$ \\
\hline
\end{tabular}

${ }^{*}$ The figure in parenthesis was percentage (\%)

BCG scar was observed by interviewer among those vaccinated by card $82.5 \%(194 / 235)$ and $77.8 \%(169 / 217)$ among those vaccinated by history. The BCG to measles dropout rate (over all drops out rate) was $38.1 \%$ and pentavalent-1 to pentavalent-1 dropout rate was $55.2 \%$.

Among studied children, immunization status of children of 12-23 months during survey were: not immunized $168(24.2 \%)$, more than half of the children partially immunized $367(52.9 \%)$ and completely immunized 159(22.9\%).
Among the potential factors identifying completely immunizing their children by using enter method: being educated mothers or care takers, health institutional delivery and others were found to be significant factors identifying of completely immunizing their children (Table 2). For those conveniences immunization services 5.19 times $(95 \% \mathrm{Cl} 2.16,12.45)$ more likely to immunize their children completely (Table 2).

Table 2: Multivariable analysis for completion of immunization (completely immunized) and selected variables of mothers/care takers of 12-23 months children in eastern Ethiopia, 2010.

\begin{tabular}{|c|c|c|c|c|}
\hline \multirow[b]{2}{*}{ Variable } & \multicolumn{3}{|c|}{ Fully Immunized } & \multirow[b]{2}{*}{ Adj.OR $[95 \% \mathrm{Cl}]$} \\
\hline & Yes & No & Crude OR $[95 \% \mathrm{Cl}]$ & \\
\hline \multicolumn{5}{|c|}{ Education Level of Mother/Care Taker } \\
\hline Illiterate & 82 & 376 & 1 & 1 \\
\hline Literate & 77 & 159 & $2.22(1.55,3.19)$ & $1.79(1.20,2.68)$ \\
\hline \multicolumn{5}{|c|}{ Knowledge on Immunization } \\
\hline Satisfactory & 144 & 264 & $9.86(5.64,17.22)$ & $6.13(3.33,11.26)$ \\
\hline Poor & 15 & 271 & 1 & 1 \\
\hline \multicolumn{5}{|c|}{ Attitude Towards Immunization } \\
\hline Positive & 155 & 469 & $5.51(2.73,11.11)$ & $3.29(1.13,9.58)$ \\
\hline Negative & 4 & 66 & 1 & 1 \\
\hline \multicolumn{5}{|c|}{ Place of Index Child Birth } \\
\hline Health institution & 45 & 72 & $2.54(1.67,3.88)$ & $1.98(1.26,3.12)$ \\
\hline Home & 114 & 463 & 1 & 1 \\
\hline \multicolumn{5}{|l|}{ Visit ANC Service } \\
\hline Yes & 102 & 268 & $1.88(1.30,2.73)$ & $1.30(0.78,2.16)^{\star}$ \\
\hline No & 53 & 262 & 1 & 1 \\
\hline \multicolumn{5}{|c|}{ Immunization Service Convenience } \\
\hline Yes & 149 & 363 & $7.06(3.63,13.73)$ & $5.19(2.16,12.45)$ \\
\hline \multicolumn{5}{|c|}{ HEW Visit House Hold (Rural) } \\
\hline Yes & 94 & 224 & $3.59(2.12,5.89)$ & $2.79(1.63,4.80)$ \\
\hline No & 23 & 97 & 1 & 1 \\
\hline
\end{tabular}


Table 3: Multivariable analysis for non-immunized and reasons for not immunizing their child in eastern Ethiopia, 2010.

\begin{tabular}{|c|c|c|c|c|}
\hline \multirow[b]{2}{*}{ Variable } & \multicolumn{3}{|c|}{ Fully Immunized } & \multirow[b]{2}{*}{ Adj.OR (95\%Cl) } \\
\hline & Yes & NO & Crude OR $(95 \% \mathrm{Cl})$ & \\
\hline \multicolumn{5}{|c|}{ Education Level of Mother/Care Taker } \\
\hline Illiterate & 82 & 376 & 1 & 1 \\
\hline Literate & 77 & 159 & $2.22(1.55,3.19)$ & $1.79(1.20,2.68)$ \\
\hline \multicolumn{5}{|c|}{ Knowledge on Immunization } \\
\hline Satisfactory & 144 & 264 & $9.86(5.64,17.22)$ & $6.13(3.33,11.26)$ \\
\hline Poor & 15 & 271 & 1 & 1 \\
\hline \multicolumn{5}{|c|}{ Attitude towards Immunization } \\
\hline Positive & 155 & 469 & $5.51(2.73,11.11)$ & $3.29(1.13,9.58)$ \\
\hline Negative & 4 & 66 & 1 & 1 \\
\hline \multicolumn{5}{|c|}{ Place of Index Child Birth } \\
\hline Health institution & 45 & 72 & $2.54(1.67,3.88)$ & $1.98(1.26,3.12)$ \\
\hline Home & 114 & 463 & 1 & 1 \\
\hline \multicolumn{5}{|l|}{ Visit ANC Service } \\
\hline Yes & 102 & 268 & $1.88(1.30,2.73)$ & $1.30(0.78,2.16)^{\star}$ \\
\hline No & 53 & 262 & 1 & 1 \\
\hline \multicolumn{5}{|c|}{ Immunization Service Convenience } \\
\hline Yes & 149 & 363 & $7.06(3.63,13.73)$ & $5.19(2.16,12.45)$ \\
\hline No & 10 & 172 & 1 & 1 \\
\hline \multicolumn{5}{|c|}{ HEW Visit House Hold (Rural) } \\
\hline Yes & 94 & 224 & $3.59(2.12,5.89)$ & $2.79(1.63,4.80)$ \\
\hline No & 23 & 197 & 1 & 1 \\
\hline
\end{tabular}

Table 4: Multivariable analysis for partially immunized and reasons for not immunizing their child in Eastern Ethiopia, 2010.

\begin{tabular}{|c|c|c|c|c|}
\hline \multicolumn{5}{|c|}{ Partially Immunized } \\
\hline Variable & Yes & NO(No) & Crude OR $[95 \% \mathrm{C}]$ & Adj.OR $[95 \% \mathrm{Cl}]$ \\
\hline \multicolumn{5}{|c|}{ Unaware of Need for Immunization } \\
\hline Yes & 232 & 153 & $5.97(3.37,10.57)$ & $5.95(3.26,10.87)$ \\
\hline No & 135 & 15 & 1 & 1 \\
\hline \multicolumn{5}{|c|}{ Unaware of Need of Return $2^{\text {nd }}$ or $3^{\text {rd }}$ Dose } \\
\hline Yes & 317 & 115 & $2.98(1.92,4.62)$ & $2.38(1.44,3.95)$ \\
\hline No & 50 & 53 & 1 & 1 \\
\hline \multicolumn{5}{|c|}{$\begin{array}{l}\text { Place and/or Time of Immunization } \\
\text { Unknown }\end{array}$} \\
\hline Yes & 128 & 90 & $2.18(1.50,3.16)$ & $2.30(1.50,3.53)$ \\
\hline No & 239 & 78 & 1 & 1 \\
\hline \multicolumn{5}{|c|}{ Fear of Side Reactions } \\
\hline Yes & 72 & 73 & $3.12(2.09,4.64)$ & $2.58(1.59,4.17)$ \\
\hline No & 295 & 95 & 1 & 1 \\
\hline \multicolumn{5}{|c|}{ Wrong Ideas about Contraindications } \\
\hline Yes & 100 & 73 & $2.03(1.39,2.97)$ & $2.00(1.23,3.11)$ \\
\hline No & 267 & 95 & 1 & 1 \\
\hline \multicolumn{5}{|c|}{ Postpone till another Time } \\
\hline Yes & 153 & 72 & $1.04(0.72,1.50)^{*}$ & $1.40(0.88,2.20)^{*}$ \\
\hline No & 214 & 96 & 1 & 1 \\
\hline \multicolumn{5}{|c|}{ Vaccinator Absent } \\
\hline Yes & 137 & 57 & $1.17(0.79,1.72)^{*}$ & $1.26(0.78,2.03)^{\star}$ \\
\hline No & 230 & 111 & 1 & 1 \\
\hline \multicolumn{5}{|c|}{ Mother/Care giver too Busy } \\
\hline Yes & 196 & 88 & $1.06(0.73,1.52)^{*}$ & $1.02(0.63,1.63)^{\star}$ \\
\hline No & 171 & 80 & 1 & 1 \\
\hline
\end{tabular}


Hussen Mohammed et al.,

\section{DISCUSSION}

Over all the immunization coverage in Kombolcha Woreda was low, as by convention the immunization coverage estimated by DPT3 or in our case Pentavalence- 3 was $33.1 \%$ which fall in low categories according to national EPI standard $(<50 \%)$, and lower than study done in Kenya which was $88 \%$, north Ethiopia $92.7 \%$, district Nigeria $88.8 \%$ and Xay district of western pacific region $72 \%$ (FMOH et al., 2004; Olumuyiwa et al., 2008; Moses et al., 2006; Kidane et al., 2003; Masaharu et al., 2007). It might be due to low access to services, inadequate knowledge of mothers/caregivers, logistic problem and high dropout rates due to absent of tracker.

Another reason that contribute for low coverage at study area was highly missed opportunities that was $38.1 \%$ that is higher when compared with study done in Mozambique, $25.7 \%$ and study done by Nugus in Oromia zone of Amhera region which was $3 \%$ (Jagrati et al., 2008; Ashene, 2005) and but lower than south Ethiopia, Wango district $46.3 \%$ (Tadesse et al., 2009). This might be, due to no proper screening done by the health personnel when mothers/care takers come to health facility with their children for preventive and curative services which supported by Illiterate urban resident mother stated that "...I gave birth at home when I brought my child to immunize at health center the health worker said that "unless you bring your immunization card that you took during your pregnancy for this child, immunization is not given for your child" then I return my home without getting immunization for my child..."

The dropout rate of pentavalent-1 to pentavalenta- 3 was $55.2 \%$ which is higher when compared to $\mathrm{WHO}$ and national standard(>10\%), national EPI cluster survey $35.5 \%$, study done in Kenya $22.6 \%$, survey done in Oromia region that was 33\% (Moses et al., 2006; Kidane et al., 2008; USAID, 2004) likewise the BCG to measles dropout rate was $38.1 \%$ which was also high when compared to study done in rural Nigeria which was $33.3 \%$, north district of Ethiopia was 23.9\% \& Wango district 32.3\% (Olumuyiwa et al., 2008; Kidane et al., 2003; Tadesse et al., 2009).

It might be due to high defaulter, lack of local motivitators for reminding/tracking and absence of health workers at health facilities which supported by the rural illiterate mother with eight children stated that "...even if I busy with home activities I taken my child to health post when I reached there the health post was closed I wait almost for two hours till no vaccinators, so without
Sci. technol. arts Res. J., Jan-Mar 2013, 2(1): 36-41

vaccination I return to my home... 20 months age but she not finished immunization..."

Among non immunized the majority of respondents $152(39.4 \%)$ unaware the need for immunization, $104(31.0 \%)$ lack of confirmed information, $87(30.6 \%)$ mothers/care takers too busy which were in line with the reasons stated in study conducted in Mali, Agra district India: $52.1 \%$ lack of awareness, $16.6 \%$ fear of side effect of vaccination (Abdel et al., 2009; Preveer et al., 2008).

Fully immunized children, 159(22.9\%) was low compared with different study that revealed in national EPI cluster survey $49.9 \%$, in Istanbul $84.5 \%$, Mali $59.9 \%$, in India $29 \%$ of children age 12-23 months are fully immunized, survey done in Oromia region $38 \%$ and Illubabor zone $65.6 \%$ (CSA et al., 2006; Abdel et al., 2009; Sebahat et al., 2006; WHO, 2005,) however some higher than according to 2005 Ethiopia demographic health survey $20.2 \%$. Low fully immunized children might be due to low educational status of mothers/ care takers, high defaulters, in adequate knowledge and low health service utilization.

Maternal education was a factor that positively influenced on child immunization completion that is literate mothers 1.78 times $(95 \% \mathrm{Cl} 1.19,2.64)$ more likely than illiterate. Similarly, maternal education has been reported in many studies as a predictor of child completion (Kidane et al., 2003; Rakesh et al., 2000).

The study tried to assess the immunization coverage and predictors of child immunization by community based survey and it identified the immunization coverage based on card and mothers/care takers history. However, the study addresses the effect of shortage of trained human powers, logistic as influencing factors of child immunization by qualitative part. Lack of logistic and adequate human resources might be the root causes of low child immunization (Berhane, 2008; Kidane et al., 2003).

Our study had also some limitations which included recall bias where mother might forget the vaccine given two of their children and result in misclassification (not, partially and fully immunized) those vaccinated by maternal history. However to reduce recall bias different strategies were informed by the interviewer are the site of vaccination given (oral, injection and scar) and at what age the child should receive specific antigen, these strategies used to assess immunization coverage (WHO, 2005; CSA et al., 2006; Olumuyiwa et al., 2008; Kidane et al., 2003). 
Hussen Mohammed et al.,

\section{CONCLUSION}

To prevent defaulters' mothers/care takers should be given due attention, encouraged and promoted during contacts and health workers should always be at health facility so that mothers/care takers are able to immunize their child fully and in addition sustainable logistic support from zonal as well as Woreda health departments should be strengthened and sustained.

\section{ACKNOWLEDGEMENTS}

The study was funded by Jimma University. We acknowledge the study community for providing us the necessary information.

\section{REFERENCES}

Abdel, K., Drissa, T., Fatouma, H. (2009). Evaluation of immunization coverage within the expanded program on immunization in Kita Circle, Mali. BMC International Health and Human Rights, 9 (Suppl 1), $13-19$.

Ashene, N. (2005). Assessment of quality of expanded program on immunization in Oromia zone of Amhera Region.

Berhane, Y. (2008). Universal childhood immunization: A realistic yet not achieved goal. Ethiopian journal of Health Development, 22(2), 146-147

Central Statistical Agency (CSA), ORC Macro, Calverton, Maryland and USA. (2006). Ethiopia Demographic and Health Survey 2005. Addis Ababa, Ethiopia.

FMOH, WHO, UNICEF. (2004). Enhancing routine immunization services in Ethiopia: Reaching Every District (RED) approach, field guide and essential tools for implementation. Addis Ababa, Ethiopia .

Forder, J.A. (2002). Attitudes towards immunization in Cambodia: A qualitative study of health worker and community knowledge, attitudes and practices in Kampong Chhnang.

Government of Ethiopia. (2007). Report on progress in implementing the world fit for children plan of action. Addis Ababa, Ethiopia.

Jagrati ,V., Caroline, D., Ilesh, V. (2008). Risk factors for incomplete vaccination and missed opportunity for immunization in rural Mozambique. BMC Public Health 8, 161-167.

Kidane, T., Tekie, M. (2003). Factors influencing child immunization coverage in a rural district of Ethiopia, 2000. Ethiopian Journal of Health Development, 17(2), 105-110.
Sci. technol. arts Res. J., Jan-Mar 2013, 2(1): 36-41

Kidane, T., Yigzaw, A., Sahilemariam, Y. (2008). National EPI coverage survey report in Ethiopia, 2006. Ethiopian Journal of Health Development, 22(2), 99-108.

Masaharu, M., Somthana, D., Kayako, S. (2007). Factors affecting routine immunization coverage among children aged 12-59 months in Lao PDR: After regional polio eradication in Western Pacific Region. Bioscience Trends, 1(1), 43-51.

Moses, N. , Karen D., Amina, I. (2006). Immunization coverage and risk factors for failure to immunize within the expanded programme on immunization in Kenya after introduction of new haemophilus influenzae type B and hepatitis B virus antigens. BMC Public Health, 6, 132-139.

Olumuyiwa, O., Ewan, A., Francois, P., Vincent, I. (2008). Determinants of vaccination coverage in rural Nigeria. BMC Public Health, 8, 381-388.

Preveer, S., Daya, P., Vartica, S. (2008). Assessment of routine immunization in urban slum of Agra district. India Journal of Preventive and Social Medicine, 39 (1\&2), 60-62.

Rakesh M., Sang-Hyop L. ( 2000). Child Immunization in Madhya Pradesh. National Family Health Survey Subject Reports Number 15.

Sebahat, D., Nadi, B. (2006). Vaccination coverage and reasons for non-vaccination in a district of Istanbul. BMC Public Health, 6, 125-132.

Tadesse, H., Deribew, A and Woldie, M. (2009). Predictors of defaulting from completion of child immunization in South Ethiopia. BMC Public Health, 9, 150-156.

Tove K, R., Vance D., Lisa C. (2008). Too little but not too late: Results of a literature review to improve routine immunization programs in developing countries. BMC Health Services Research, 8, 134148.

USAID. (2004). Essential services for health in Ethiopia and Oromia region, house hold survey. Addis Ababa, Ethiopia.

WHO. (2006). Challenges in global immunization and the global immunization vision and strategy 20062015. Weekly Epidemiological Record, 81(9), 189196.

World Health Organization. (2005). Immunization coverage cluster survey reference manual. Immunization, Vaccines and Biological. Geneva. 